\title{
Explorations on IT Majors' Talents Cultivation Supported by Open Source Software
}

\author{
ZHU Zemin1 and Zhang Qing1 \\ 1 Computer School, Huanggang Normal University, Huanggang,China
}

\begin{abstract}
Open source software has been widely used in the education industry. To construct educational informationization system and to be developed into educational resources are the most popular forms. This paper analyses the positive role of open source software in IT education firstly. Then, from two perspectives, the open source forum and open source case base, it explores how to promote the students' software development technology and professional skills. College Open Source Forum is an open-source technology community which is for college students of IT Major and fans who are interested in software development. The construction of open source case base is conducive to provide more practice opportunities for students. These two ways of open source software help improve the quality of IT professional training.
\end{abstract}

\section{Introduction}

Open-source software (OSS) is computer software with its source code made available with a license in which the copyright holder provides the rights to study, change, and distribute the software to anyone and for any purpose. (wikipedia)

Open source software was firstly developed in the United States, Finland, and other western countries where the software industry is relatively developed. LAMP (Linux+Apache+MySQL+PHP) is a typical example of the successful open source software. Open source activities are mainly organized by communities that have common interests. At present, Sourceforge and Opensource are the most famous open source communities in the world.

In recent years, although open source activities have made great progress in China, there is still a wide gap compared with Western developed countries. The development of open source software is obviously inconsistent with GDP growth in China. The better thing is that the situation is changing, and the publicity and research of open source software is increasingly deepened. The number of papers related to open source software shows an obvious increasing trend. (Feng Guohe, 2010) At present, there have been some influential open source forums in China, such as oschina.net, which has made great contributions to the popularity of open source software in China.

Open source software applied in the education industry has achieved significant development. These applications are mainly divided into these categories: to construct educational informationization system, to serve as an educational resource for teaching, and to improve software development technology and professional skills by the open source community exchange. (Vaclav Petras, 2015; WANG Zhiyong, 2017; Li Xujia, 2017) At present, there have been some explorations about open source software serving IT professional education, but it is not deep enough. This article shares two of the author's practices in this area.

\section{The positive role of open source software in IT education}

In the talent training process of software engineering, computer science and technology, and other majors, open source software and open source community exchanges can help to cultivate students' professional skills and entrepreneurship.

To help students master a new informationization construction plan. The policy of copyright protection in foreign countries is more perfect. In order to reduce costs, more educational institutions tend to choose open source software. At the same time, these open source software is continuously updated and improved due to the large number of users' participation. This process publicized the concept of open source to students in an invisible way.

It will help students achieve all-round development of their knowledge, ability and quality, and develop their ability to discover, analyse, and creatively solve problems, not just programming skills. We can build the open source community as the second classroom for the training of students' professional abilities, engage students to participate in the open source activities supported by the open source community. The

\footnotetext{
*Corresponding author: 16650709@qq.com, 823963996@qq.com
} 
communities make teachers and students break the restrictions of the school wall, build team cooperation and communication, and develop high quality software products.

The open source project is more suitable for leading students to understand the survival rules of the future world. The open source project does not mean free, but means that the project can be freely used under a certain copyright policy and continuously developed on the basis of others' achievements. It not only saves development costs, but also quickly accesses new ideas and expands new insights. Open source projects advocate an open and sharing spirit.

To cultivate students' awareness of intellectual property rights. Unfortunately, there is some pirated commercial software in practical teaching, which we should prohibit. The use of open source projects does not have this problem at all. It can also cultivate students' awareness of intellectual property protection and encourage students to develop innovative ideas.

\section{Construction of Open Source Forum in Colleges}

\subsection{The Orientation Of Open Source Forum In Colleges}

The College Open Source Forum is an open source technology community for university IT students and software developers. It aims to provide an exchange platform for IT students, teachers, and like-minded professional technicians. Through the College Open Source Forum, we can promote open source concepts, promote successful open source software projects, serve the talents of IT majors such as university software engineering, and build a platform for inter-school open source software cooperation and development. Launching open source activities in colleges and universities is conducive to improve students' interest, learning awareness and autonomy. It can also help to open up students' vision, deepen students' professional learning, cultivate students' sense of innovation and teamwork, and instil students' sentiments of "participation, dedication, and selflessness". Students can accumulate technology and develop successful software projects through open source. Not only can they attract software companies to invest, but they can also start their own businesses.

\subsection{Development of Open Source Forum}

Forum domain name registration: Take the first three letters "OSS" in Open Source Software, which is consistent with the choice of other mainstream open source forum domain names. In order to highlight the positioning, which is the initial stage in the study of open source software and mainly for college student groups, we add a "123" suffix behind "OSS". Finally we choose www.oss 123.cn as the domain name of the forum.
Forum software selection: The College Open Source Forum is implemented with Discuz. Discuz is one of the largest community software and service providers in China. Discuz is very good in terms of function, stability, load capacity, safety guarantee and so on. According to its policy of copyright, Discuz can freely use and modify source code and interface style as long as it is not used for commercial purposes.

\subsection{Column Design}

The basic rules for the column design are to highlight open source themes and to serve teachers and students in colleges.

Open source 123: The purpose of "Open Source 123" is to introduce open source software, open source concepts and other basic knowledge of open source. Subsection "Open Source Here" introduces the basics of open source. "Open Source Genius" introduces people who have achieved great success in open source software. "Open Source Works" introduces the world's more successful and well-known open source software works.

Open Source Project in Colleges: The "Open Source Project in Colleges" is the core section of the forum. Open source projects that students host and participate in can all be published here. Open source projects can be freely developed by using any programming language. In order to facilitate access and communication, the forum is divided into subsections according to popular programming languages or domain classifications, such as JAVA, PHP, database, front-end web developer, Operating System and so on.

Works and Services: This Column is divided into some sub-columns includes "Students' Open Source Works", "Project Rewarded", "IT Training" etc. "Students' Open Source Works" is mainly used to publish and promote students' successful works, and these works are required to be published in open source. Software demanders, such as enterprises, can publish their own requirements to the "Project Rewarded", where technical personnel can take orders and receive certain rewards therefrom. "IT Training" is used to provide students with information such as training skills and technical exchanges which are free or with paying.

\section{Construction of open source software Education Resources Case Base}

\subsection{Organization of case base}

Open source software for education is very rich, so they should be organized and managed by appropriate programs to improve the utilization and accessibility of case resources. The curriculum system of talent training program, development language, or application area is a common organization method of the case base. There are many advantages to organize open source software education resources according to curriculum. It is more suitable for the realization of talents training goals, and is also conducive to the popularization and application in 
teaching. In practice, several related courses can also be combined to build a more comprehensive case and improve students' comprehensive application ability.

\subsection{Construction of case base of JAVA Programming}

The following uses the "JAVA Programming" course as an example to introduce the construction of case base. Through long-term accumulation, the case of the "JAVA Programming" course has been relatively rich. According to its granularity, it can be divided into knowledge level, comprehensive level, and application level.

Knowledge level case: These cases are designed for enabling students to understand a new knowledge point. Usually the examples of textbooks fall into this case. In the course of teaching, teachers can choose and supplement differently based on the students' learning level and ability level.

Case 1 was designed to make students understand the knowledge of "Reading and writing files by bytes". Case 1 also requires students to rewrite program to copy files by characters, so as to achieve the purpose of practicing multiple knowledge points through a case.

Case 1: Copy the file "Beijing.mp3" to the same folder by bytes and name it "Welcome to Beijing.mp3".

Comprehensive level case: A comprehensive level case usually takes place after a chapter, a knowledge unit and a course. The case is designed for applying, consolidating and improving the knowledge of the unit. It can be designed individually, or a part of a large-scale application. The comprehensive level case can help students experience the development of industry level software project, and improve students' programming awareness.

After learning the chapter of the graphical user interface, Case 2 was designed.

Case 2: To write a calculator test software to train pupils' arithmetic skills. The program consists of 3 classes. Teacher is responsible for giving the mathematics question and determining whether the answer is correct. ComputerFrame is responsible for providing views for arithmetic examination questions and views for question answering. TestComputerProgram is the main class of software. (Omit the source code here)

Case 2 integrates knowledge of graphical programming, event processing, and use of class(JFrame, JButton, etc). The subject of the case is practical and interesting. The case also allows students to expand the functions of multiplication and division for this program.

Application level case: It requires teachers to design the course issue around the needs of an application, and then requires students to apply the knowledge of the course and related courses. Application-level cases can also be obtained by transforming actual software systems from companies that do not involve trade secrets, open source software with moderate scale and difficulty, or imitating existing application systems. The subject of the case is better to be more interested in the students, for example, game development.
When "JAVA Programming" course was over, many cases involving different themes are provided to students. Students choose one to finish according to their own interests. They are also encouraged to design creative projects. Here are some cases that are often chosen by the students.

Case 3: Gobang. It supports two people to play (using the mouse), and it can judge the victory or defeat.

Case 4: Calendar Notepad. Calendar Notepad is a calendar with schedule reminder. It allows users to record every day would like to see as anything, just click on a date then you can re-write the right things. Users can query all the tips of a month.

Case 5: Typing training and testing software. Write a software application to learn and practice typing. It can test user's the error rate and the average typing speed.

Case 6: Analog scientific calculator. Its view simulates a calculator program in Windows. It can implement basic math operations, functions, such as addition, subtraction, multiplication, division, factorial, sine, cosine, and exponentiation operations.

Case 7: Simulation Mine Sweeper. Its views simulate Minesweeper in Windows.

\subsection{Several Considerations of Case Base Construction}

Open source software must be used within the scope permitted by copyright, which helps students create copyright awareness.

Not all open source software codes are suitable for IT beginners, so open source software should be selected from features, code styles, and code readability. Students learn and add-on functions 'development by observing the source code. The elegant code will inspire the students.

Case study will improve students' software development capabilities, but it will never replace the importance of their own research and development. Teachers must guide students to study open-source code and do more with their own hands.

\section{Conclusions}

Exchanges through open source community and research on open source software itself are effective ways to improve software development skills and professional skills for IT Majors. This article explores the strategy that open source software helps to cultivate IT professionals from two aspects: the establishment of open source forums for colleges and the construction of open source teaching cases for IT Majors.

Open source software serving IT education is a longterm work that requires constant exploration, exchange, and reflection. For instances: How to increase IT interest, learning awareness, and autonomy of IT majors, open up their vision, and deepen their professional learning through open source forums in colleges? How to promote the college teaching reform for IT majors and improve teaching quality and school influence through their participation of open source activities? How to cultivate 
students' professional quality, enhance students' awareness of innovation and teamwork, and cultivate the sentiment of "engagement, dedication, and selflessness" of college students through open source activities? Actually, many issues need to be done.

\section{Acknowledgements}

This work is partially supported by Key Teaching Research Projects of Huanggang Normal University (Project No. 2016CE10) and Hubei Education Science 12th Five-Year Plan: The organization of software open source activities in universities and its role in the training of IT talents (Project No. 2014B215).

\section{References}

1. Open-source software. https://en.wikipedia.org/wiki/Open-source_software

2. Feng Guohe. Bibliometric Analysis of Open Source Software Published During the Period of 2000 -2009. Library and Information Service, vol.2, 2010,pp. 5054

3. Li Xujia. Significance of constructing university MOOC education based on open source software and suggestions. China Medical Education Technology, Vol.31 No.4, Aug. 2017, pp. 441-445

4. WANG Zhiyong. Reforming of the Practice Teaching in the Course of Microwave Remote Sensing Assisted by Open Source Software. Bulletin of Surveying and Mapping, No.3, 2017: 137-140.

5. Vaclav Petras, Anna Petrasova, Brendan Harmon, Ross K. Meentemeyer and Helena Mitasova. Integrating Free and Open Source Solutions into Geospatial Science Education. ISPRS Int. J. Geo-Inf. 2015, 4, 942-956 